\title{
CEVIPOF
}
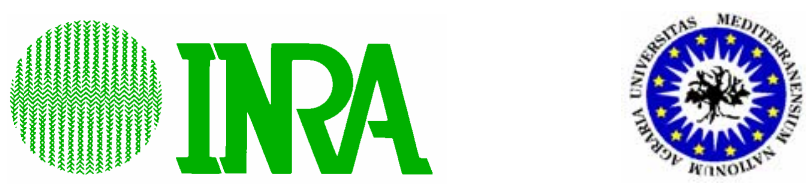

\section{LES MONDES AGRICOLES EN POLITIQUE}

\author{
Séminaire de recherche interdisciplinaire (octobre 2006 - novembre 2007)
}

Minoritaires et segmentés, localisés et mondialisés, encore spécifiés dans leurs comportements mais dispersés dans l'échelle des revenus, ancrés à droite mais volatiles comme le reste de l'électorat, hostiles à une renationalisation des politiques agricoles mais également éloignés du projet européen postérieur à l'élargissement, les agriculteurs voient leur identité et leur place se recomposer à travers une palette de « mondes agricoles » distincts.

Pour caractériser un tel parcours et comprendre les bouleversements enregistrés, il convient de revisiter les appartenances de ce groupe professionnel aux dimensions multiples : son insertion internationale et sa vision européenne, son univers syndical et institutionnel, ses tropismes politiques, son rapport au marché et aux politiques publiques...

L'objectif général de cette démarche est, in fine, de développer et capitaliser les connaissances qui permettront de mieux comprendre les ruptures et permanences dans l'univers politique et professionnel des agriculteurs français depuis le milieu des années 80 .

\section{— Un séminaire interdisciplinaire d'une durée d'un an}

Ce projet se traduira, dans un premier temps, par un séminaire interdisciplinaire au cours duquel sera dressé un bilan des connaissances existantes ainsi que de l'outillage théorique et méthodologique disponible.

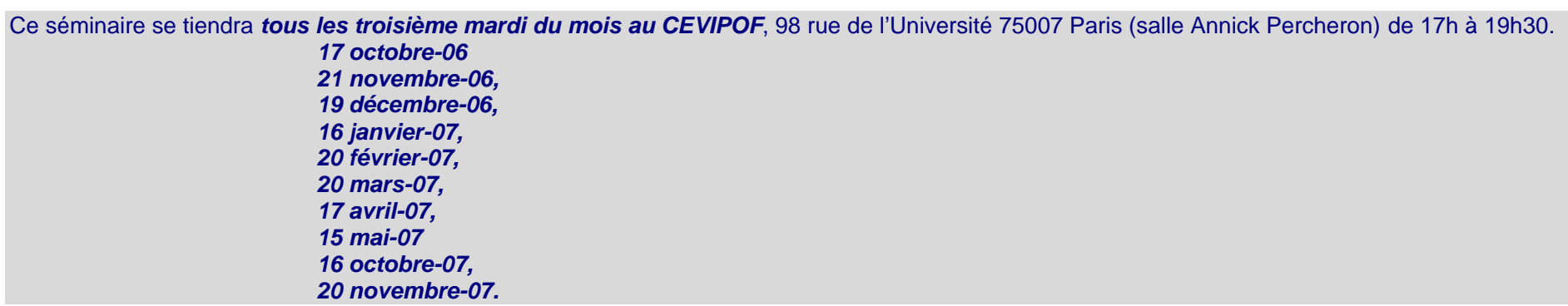

Ces séances seront l'occasion de revenir (de façon réflexive et synthétique) sur des recherches déjà réalisées mais également de présenter de nouveaux travaux, même inachevés. Largement ouvert à la communauté scientifique (chercheurs confirmés et étudiants), ce séminaire pourra également accueillir ponctuellement des acteurs : élus, syndicalistes, associatifs,... II offrira une large place aux travaux des jeunes chercheurs et fera appel à des grands témoins venant d'horizons extérieurs aux communautés scientifiques « ruralistes » et françaises.

Les 10 séances du séminaire s'articuleront autour de six volets (le programme et la problématique détaillés seront mis en ligne ultérieurement sur le site du CIHEAM : www.ciheam.org).
o Volet 1. Agriculteur(s) : des identités professionnelles sous influences.
o Volet 2. Les agriculteurs, le marché et la politique
o Volet 3. Organisations, engagements et représentations professionnelles
o Volet 4. Radiographie électorale du « vote agricole »
o Volet 5. Modes et niveaux de l'action publique
o Volet 6. Nouvelles conjugalités, espaces familiaux et rapports de genre

\section{- Un colloque et une publication en perspective}

Un colloque est programmé pour le $\mathbf{1}^{\text {er }}$ semestre 2008 : sans découler directement du séminaire, il sera l'occasion d'en restituer et de mettre en débat ses principaux résultats à travers des approches interdisciplinaires, comparées et intergénérationnelles. Une publication aux presses de Sciences Po viendra, à l'horizon 2008/2009, clore et restituer l'ensemble de cette démarche.

Ce séminaire, ce colloque et cette publication constitueront la quatrième édition d'une série de travaux et de colloques organisés en 1956,1970 et 1987 sur la place des agriculteurs dans la vie politique française.

\section{- Comité de pilotage}

Bertrand Hervieu (CIHEAM), Nonna Mayer (AFSP-CEVIPOF), Jacques Rémy (INRA), Pascal Perrineau (CEVIPOF), François Purseigle (CIHEAM), Nicolas Durand (INRA)

Renseignements : François Purseigle,

CIHEAM-11, rue Newton-75116 PARIS

Tel : 33(0)1-53-23-91-13, Fax : 33(0)1-53-23-91-01/02

E mail : purseigle@ciheam.org 